\title{
The Highest Subject Restriction and the Pro-drop Parameter in Arabic
}

\author{
Issa Abdel Razaq* \\ Department of English Language \& Literature - Isra University, P. O. Box-22-23-Postal Code Amman 11622, \\ Jordan. \\ *Corresponding Author: Issa Abdel Razaq, Department of English Language \& Literature - Isra \\ University, P. O. Box-22-23_Postal Code Amman 11622, Jordan. Email: issa.abdelrazaq@iu.edu.jo
}

\begin{abstract}
The aim of this paper is to defend the claim that the Highest Subject Restriction is not an independent constraint that applies universally to all resumptive languages. Instead, the paper develops an analysis based on data from relative clauses in Jordanian Arabic and similar dialects that reduces the HSR into the familial pro-drop parameter that is operative in Arabic. Evidence that this is indeed the case comes from two main observations about the SV word order being a topic-comment construction and the pro-drop parameter in Arabic. The paper concludes that relative clauses in the Levantine dialects do contain a subject resumptive pronoun, albeit one that is not overtly spelled out.
\end{abstract}

Keywords: Highest Subject Restriction, Arabic dialects, resumptive pronouns, pro-drop parameter.

\section{INTRODUCTION}

It is well known that many languages with resumption display restrictions that regulate the distribution of resumptive pronouns (RPs, henceforth). One of the traditional restrictions in the literature on resumption is the Highest Subject Restriction dubbed by McCloskey (1990) [1]. The Highest Subject Restriction prohibits RPs in the highest subject position in unbounded dependencies. McCloskey (1990, 2002, 2006, 2011) [2]-[4] argues for the Highest Subject Restriction in Irish relative clauses illustrated in the following examples.
1a. *an fear a raibh sé breoite the man comp pro be-past he ill 'The man that (he) was ill'
b. *na daoine a rabhadar pro breoite the people comp pro $_{\text {be-past-3pl ill }}$ 'The people that (they) were ill'

According to McCloskey, RPs in Irish may occur in various syntactic positions of unbounded dependencies except for the highest subject position as shown in (1a-b). Similar facts from other languages have also been reported. According to Shlonsky (1992, 2002) [5]-[6], Palestinian Arabic (PA, henceforth) and Hebrew are subject to the HSR. In both languages, the only position from which RPs are banned is the highest subject position. Consider the following examples from Hebrew and PA, respectively.

2a. *ha-Piš še-hu Pohev vet Rina the-man that-he love Acc Rina 'the man who loves Rina'

b. ha-Piš še Pohev vet Rina the-man that love Acc Rina 'the man who loves Rina' 


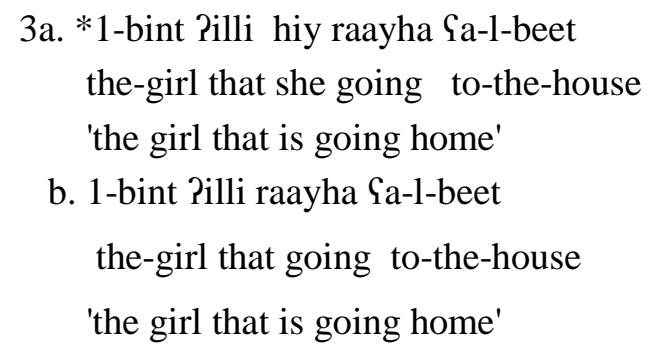

McCloskey and Shlonsky provide different accounts to capture the HSR effects in the languages above. Following Borer (1984) [7] and Aoun and Li (1989) [8], McCloskey (1990, 2002, 2006) treats the HSR as the equivalent of Principle B of the Binding Theory in the domain of A-relations between RPs and their antecedents. In both types of relations, (resumptive) pronouns cannot be locally bound. Shlonsky (1992) opts for a different explanation whereby the HSR is analyzed as a property of C that identifies its Spec position as an A-position (Shlonsky 1992). Movement from the highest subject position, i.e., Spec,IP, to Spec,CP is available, hence, obligatory and no RP is allowed. Shlonsky claims that RPs are inserted only when movement is unavailable as a last resort strategy.

Since its conception, the HSR has been shown to apply to a wide range of resumptive languages such as Irish (McCloskey 1990, 2002, 2006), Welsh (Willis 2000) [9], Hebrew (Shlonsky 1992, Demirdache 1997 [10]), Dinka (Klein 2014 [11], 2016 [12]), Palestinian Arabic (Shlonsky 1992, 2002), among many others ${ }^{1}$. Consequently, these studies treat the HSR as an independent constraint regulating the distribution of RPs in languages with productive resumption. Nevertheless, the HSR is not a universal constraint. There are languages in which RPs are used productively but do not display the HSR effects. In Jordanian Arabic (JA, henceforth), for instance, RPs are not blocked in the highest subject position, unlike Palestinian Arabic (Shlonsky 1992). Consider the following examples.

4a. Juf-na 1-fannaan Pilli rasam hay l-lawha

saw-1pl the-artist who painted.3ms this the-painting

'We saw the artist who painted this painting.'

b. Juf-na l-fannaan Pilli huwa rasam hay l-lawha

saw-1pl the-artist who he painted.3ms this the-painting

'We saw the artist who painted this painting.'

5a. et-tollaab Pilli sajjalo l-mawaad laazim ydhallo

the-students who registered. $3 \mathrm{mpl}$ the-courses must stay. $3 \mathrm{mpl}$

'The students who registered the courses must stay.'

b. et-tollaab Pilli hummu sajjalo 1-mawaad laazim ydhallo

the-students who they registered. $3 \mathrm{mpl}$ the-courses must stay. $3 \mathrm{mpl}$

'The students who registered the courses must stay.'

Lebanese Arabic (LA), too, exhibit the same behaviour as Jordanian Arabic. Aoun, Hornstein and Choueiri (2001) [13] observe that Lebanese Arabic strong pronouns are not subject to the HSR. They can be related to their antecedents within the same CP. Consider the following examples.

6a. ba9rif l-walad yalli huwwe nfaћat l-yom

know.1s the-boy that he expelled.3ms today

'I know the boy who was expelled today.'

b. t?asas 1-walad yalli huwwe $\chi$ azza? 1-kteeb

Punished.3ms the-boy that he tore. $3 \mathrm{~ms}$ the-book

'The boy who tore up the book was punished.'

${ }^{1}$ See Klein (2014) and (2016) for a typology of resumption in a wide range of languages. 
Based on such facts, this paper argues against treating the HSR as a general linguistic principle ${ }^{2}$. Instead, the paper develops an analysis that reduces the HSR into the familial pro-drop parameter that is functional in (Jordanian) Arabic. It will be demonstrated that absence of RPs in subject positions is a direct result of the rich verbal agreement. That is, the verb carries the features necessary for the identification of subject pronouns, hence their presence become syntactically redundant. This approach leads to the correct characterization of the behaviour of subject RPs in relative clauses and other A'-constructions. As such, the paper re-examines data from PA provided in Shlonsky (1992, 2002) and argues against the assumption that the HSR holds in this dialect. Instead, it will be shown that PA RPs displays the same behaviour seen in JA and LA, all of which form the Levantine family.

\section{Distribution of SubJeCt RPs: Methods AND MATERIALS}

This section examines and compares the distribution of RPs in subject positions in two Levantine Arabic dialects, namely Palestinian Arabic (PA) and Jordanian Arabic (JA). The data collected for this study falls into two sets reflecting the two types of sentence found across the Arabic dialects. The first set of data is concerned with the HSR effects in the context of verbal sentences. Meanwhile, the second set of data considers the HSR effects in contexts that have not been reported before, i.e., contexts of verbless sentences, that I believe will be of significant importance to any analysis of Arabic RPs.

\subsection{Subject RPs in Verbal Sentences}

Starting with Palestinian Arabic as reported in Shlonsky (1992, 2002), RPs are not allowed to occur in the highest subject position in relative clause constructions. Shlonsky provides the following examples showing that PA obeys the HSR.

$$
\begin{aligned}
& \text { 7a. *1-bint Pilli hiy raayha @a-l-beet } \\
& \text { the-girl that she going to-the-house } \\
& \text { 'the girl that is going home.' } \\
& \text { b. 1-bint Pilli raayha 9a-1-beet } \\
& \text { the-girl that going to-the-house } \\
& \text { 'the girl that is going home.' }
\end{aligned}
$$

The difference between the two examples above lies in the use of a subject RP in the highest subject position within the relative clauses in the former. According to Shlonsky, PA does not tolerate RPs in this position of a relative clause.

Although the HSR appears to prohibit RPs in the highest subject position, other subject positions behave differently. In embedded subject positions, for instance, RPs are reported to be obligatory in PA. Consider the following examples that Shlonsky (1992) provides.

$$
\begin{aligned}
& \text { 8a. 1-bint } ? \text { illi fakkarti?inno hiy raayha } \text { 9-al-beet } \\
& \text { the-girl that thought.2f that she going to-the-house } \\
& \text { 'the girl that you thought that (she) is going home.' } \\
& \text { b.* 1-bint Pilli fakkarti Pinno raayha } \text { S-al-beet } \\
& \text { the-girl that thought.2f that going to-the-house } \\
& \text { 'the girl that you thought that (she) is going home.' }
\end{aligned}
$$

In cases of embedded subject positions like the ones here, only subject RPs must be present as shown in (8a). Unlike cases of the highest subject position, gaps cannot occupy embedded subject positions in PA (8b).

On the other hand, the distribution of RPs in JA appears to be less restricted than PA. Unlike PA, RPs are not disallowed in the highest subject position in relative clauses. Either a RP or a gap may occupy this position as shown in the sentences below.

${ }^{2}$ Other languages in which the HSR does not hold are: Vata and Yoruba reported in Rouveret (2011) [14] and Asudeh (2012) [15]. 
9a. Juf-na 1-fannaan Pilli rasam hay l-lawha saw-1pl the-artist who painted.3ms this the-painting 'We saw the artist who painted this painting.'

b. Juf-na 1-fannaan Pilli huwwa rasam hay l-lawha saw-1pl the-artist who he painted.3ms this the-painting

'We saw the artist who painted this painting.'

10a. et-tollaab Pilli sajjalo l-mawaad laazim ydhallo the-students who registered. $3 \mathrm{mpl}$ the-courses must stay. $3 \mathrm{mpl}$ 'The students who registered the courses must stay.'

b. et-tollaab Pilli hummu sajjalo 1-mawaad laazim ydhallo the-students who they registered, $3 \mathrm{mpl}$ the-courses must stay. $3 \mathrm{mpl}$ 'The students who registered the courses must stay.'

Although cases in which gaps are more common in JA as in (9a and 10a) above, the ones in which RPs are present are all acceptable (9b and 10b).

As for embedded subject positions, subject RPs in JA display the same behavior observed in the highest subject position cases. To illustrate, consider the following examples.

11a. Juf-na l-fannaan Pilli fakkarto Pinno rasam hay l-lawha saw-1pl the-artist who thought. $2 \mathrm{pl}$ that painted.3ms this the-painting 'We saw the artist who you thought that he painted this painting.'

b. Juf-na l-fannaan Pilli fakkarto Pinno huwwa rasam hay l-lawha saw-1 pl the-artist who thought.2pl that he painted.3ms this the-painting 'We saw the artist who you thought that he painted this painting.'

12a. jama3na et-tollaab?illi GrefnaPinno sajjalo 1-mawaad gathere. $1 \mathrm{pl}$ the-students who knew.1pl that registered.3mpl the-courses 'We gathered the students who we knew that they registered the courses.'

b. jama3na et-tollaab Pilli Grefna Pinno hummu sajjalo l-mawaad gathere.1pl the-students who knew.1pl that they registered.3mpl the-courses

'We gathered the students who we knew that they registered the courses.'

In the sentences above, embedded subject positions may or may not be filled with RPs. Either case, the sentences are well-formed.

\subsection{Subject RPs in Non-Verbal Sentences}

The other environment any analysis of the HSR effects in Arabic has to take into account involves contexts of verbless sentences that are quite common across the dialects of Arabic. These are sentences that contain a subject and a predicate that can be a noun phrase, an adjective phrase or a prepositional phrase, but without a verb (see Eid 1983 [16], Eid 1992 [17]; Benmamoun 2000 [18]; and Aoun, Benmamoun and Choueiri 2010 [19]). In such contexts, the data collected from JA and PA for this study shows that RPs are obligatory in the (highest) subject position as shown in the examples below.

\section{3a. 1-ktaab Pilli huu Pli daye3 the-book that it mine lost 'The book that is mine is lost.'}




$$
\begin{aligned}
& \text { b. *l-ktaab Pilli Pli daye3 } \\
& \text { the-book that mine lost } \\
& \text { 14a. Sami Pilli huu zameeli safar imbaariћ } \\
& \text { Sami who he colleague-mine left.3ms yesterday } \\
& \text { 'Sami who is my colleague left yesterday.' } \\
& \text { b. *Sami Pilli zameeli saafar imbaariћ } \\
& \text { Sami who colleague-mine left.3ms yesterday }
\end{aligned}
$$

In this type of sentence, the relativized DP must be resumed overtly by a subject RP as in (13a) and (14a); absence of a RP in the highest subject position renders the sentences unacceptable as in (13b) and (14b).

To recap, this section has compared the distribution of RPs in PA (as reported in Shlonsky 1992, 2002) and JA. It has shown that while PA seems to observe the HSR in the context of verbal sentences, JA shows more flexibility in that it allows both RPs and gaps to occupy the highest subject position. As for embedded subject positions, presence of subject RPs is obligatory in PA, but optional in JA. In the context of non-verbal sentences, both PA and JA display the same behaviour in that subject RPs are obligatory when such sentences relativized. A discussion of these observations follows in the next section.

\section{DISCUSSION AND ANALYSIS}

In spite of the fact that various languages have been shown to obey the HSR, one cannot generalize it as an autonomous linguistic principle that governs the distribution of RPs in all languages. In fact, even in languages that have been shown to display typical HSR effects, re-examination has shown that the HSR is not as robust as one is lead to think. For instance, Demirdache (1997) provides an LFmovement analysis for RPs and convincingly argues that the HSR can be derived from standard locality constraints on movement. Under here analysis, the That-trace effect and the HSR are two sides of the same coin. More recently, Baoill and Maki (2012) [20] counter McCloskey's original work on the HSR in Irish and provide empirical evidence that leads to the cancellation of the HSR in certain contexts that have not been reported in McCloskey (1990).

In this section, I pursue this line of reasoning and argue that the presence or absence of the HSR effects do not have anything to do with the HSR, but are rather language specific properties that interact at the syntactic-semantic interface. The fact that RPs display different behaviour in the various subject positions indicate that the HSR is not the right restriction to capture their distribution in relative clauses in Arabic. To properly characterise the distribution of RPs in subject positions in Arabic, two observations lead the analysis developed here: one concerns SV orders and the other the null-subject parameter. These are discussed in the next two subsections.

\section{1. $\mathrm{SV}$ is a Topic-Comment Construction}

The analysis proposed here starts with the observation that JA and similar dialects display two alternating word orders: SV (O) and VS (O). Each order is associated with certain syntactic and semantic properties that distinguish it from the other. Putting aside the VS order for the time being, my hypothesis is that the (more common) SV order in Arabic dialects is a topic-comment construction, referred to as Clitic Left Dislocation (CLLD) in recent literature (Aoun and Benmamoun 1998 [21], and Aoun, Benmamoun and Choueiri 2010). In this type of construction, S or the initial DP is not the real subject, but rather a topic that is base-generated in the left peripheral position, typically Spec,TopP. Meanwhile, the real subject is a null RP, that is also base-generated within the thematic shell, with which the initial DP is coreferential.

To substantiate the hypothesis that SV orders are topic-comment constructions, several arguments can be presented. The first argument comes from the syntactic position occupied by the $\mathrm{S}$ element. The left-most position is the position reserved for topics in Arabic which is exactly what we see in SV orders. Simultaneously, a property that is characteristic of topics in Arabic is definiteness, a fact that can also be ascertained in SV sentences in which the S element is always definite. Indefinite NPs can only appear in VS order but not in the SV order, hence they cannot be used as topics. The following examples illustrate the case in hand. 


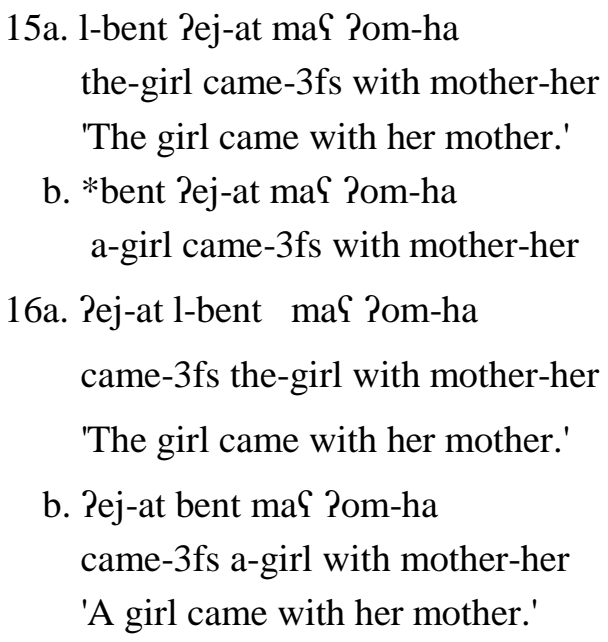

While the sentences in (15) illustrate the SV order, the ones in (16) illustrate the VS order. These examples show that while the VS order allows for a definite and an indefinite subject as in (16a) and (16b), respectively, the SV order allows only for definite arguments in the left-most position (15a).

Another argument that SV sentences are topic-comment constructions is based on the fact that topics bear a topicality feature that distinguish them from other elements in the sentence. Such a property can also be detected in SV orders whereby the $\mathrm{S}$ element bears emphatic force that manifests itself against the event presented. In (15a) above, emphasis is placed on the 'the girl' coming with her mother. Contrast this with the VS order where emphasis is not placed on 'the-girl' bur rather on the event of 'coming' itself (16). These are some of the properties that characterise topic-comment constructions in general including the SV structures. There is yet another property that is always associated with such constructions and one that is crucial for the current analysis. The following subsection sheds more light on this property.

\subsection{Arabic is a Null-Subject Language}

Under the present hypothesis, the subject in $\mathrm{SV}(\mathrm{O})$ sentences is a null RP, i.e., pro. Evidence that this is indeed the case comes from contexts where pro is lexicalized. As is well-known, a salient property of Topic-comment constructions is the use of a resumptive element that holds a coreference relation with the initial DP. In our case, the resumptive element would be, following Soltan (2007) [22], a subject pronoun that is base-generated in the external argument position within the thematic $v \mathrm{P}$ shell (Chomsky 1995) [23]. The initial structure before any syntactic operations take place can be illustrated in (17) below:

$$
\text { 17. [TорР/CP DP [TP [vP [ }
$$

The standard generalization about subject pronouns in Arabic dialects is that they are not realized at the PF interface (Kenstowicz 1989 [24], Fassi-Fehri 1993 [25], Mohammad 2000 [26], Benmamoun 2000, Aoun, Benmamoun and Choueiri 2010.). That is, Arabic is a pro-drop or a null-subject language. The subject pronoun receives a null spell-out due to the fact that the subject can be identified via agreement features carried by the verb. Nevertheless, subject pronouns can be phonetically realized in contexts that involve emphasis on the role of the subject in the information structure of the whole sentence. To illustrate this point, consider the following examples.

$$
\begin{aligned}
& \text { 18a. raah-at. } \\
& \text { left-3fs } \\
& \text { 'She left.' } \\
& \text { b. HIYYE raah-at. } \\
& \text { SHE left-3fs } \\
& \text { 'SHE left.' } \\
& \text { 19a. fataho l-baab } \\
& \text { opened.3pl the-door } \\
& \text { 'They opened the door.' }
\end{aligned}
$$




\section{b. HUMMU fataho l-baab \\ THEY opened.3pl the-door \\ 'THEY opened the door.'}

The (a) examples in each pair of the sentences above represent the unmarked alternative where pronominal subjects are not spelled out at the PF interface. As can be noticed, rich agreement on the verb makes it possible to identify (features of) the subject. Meanwhile, overt realization of the pronominal subject is always associated with emphasis and/or contrastive focus as illustrated in the (b) examples (subject pronouns are capitalized to highlight this property).

The other environment in which subject pronouns must be spelled out is coordinate structures. In such structures, presence of subject pronouns in the conjoined clauses is obligatory at the PF interface (See Soltan 2007).

$$
\begin{aligned}
& \text { 20a. hiyye raah-at o huwwa Paja. } \\
& \text { she left-3fs and he came.3ms } \\
& \text { 'She left and he came.' } \\
& \text { b. *raah-at o Paja. } \\
& \text { left-3fs and came.3ms }
\end{aligned}
$$

To recap, this section has pursued one line of analysis that reduces the HSR into language specific rules, rather than treating it as an autonomous universal constraint. As such, our discussion has focused on two observations that give more substance to the approach developed here and in the subsequent sections. The first observation concerns the SV order in Arabic and the view that it is a topic-comment construction, as opposed to the standard VS order. The second observation discussed comes from subject-verb agreement facts in Arabic. Such rich agreement system entails that subject pronouns in Arabic are dropped in all verbal sentences, unless discourse factors, such as emphasis and focus, require overt realization of these pronouns. In what follows, the discussion continues and links these observations with the relativization facts presented earlier in this study.

\subsection{Relativization from $\mathrm{SV}$ is Relativization from Topic-Comment Constructions}

Given the analysis presented above, let us now consider relativization facts concerning subject RPs. Recall that JA does not obey the HSR, subject RPs alternate with gaps in the highest subject position. Under the present analysis, this alternation is understood as follows.The structure that feeds the relativization process is a SV structure. SV structures are treated here as topic-comment constructions in which the S element stands for the DP topic that is followed by a complete predicational unit containing a subject RP and a verbal predicate. The element that undergoes relativization is the DP topic. In turn, this DP is related to a resumptive subject pro. In other words, the RP exists in the structure before relativization takes place, albeit one that receives a null phonetic spell-out at the PF interface.This would account for cases where a gap occurs in the highest subject position.

$$
\begin{aligned}
& \text { 21a. Juf-na 1-fannaan Pilli pro rasam hay l-lawha } \\
& \text { saw-1pl the-artist who pro painted.3ms this the-painting } \\
& \text { 'We saw the artist who painted this painting.' } \\
& \text { b. et-tollaab Pilli pro sajjalo l-mawaad laazim ydhallo } \\
& \text { the-students who pro registered.3mpl the-courses must stay.3pl } \\
& \text { 'The students who registered the courses must stay.' }
\end{aligned}
$$

Under the present analysis, the gap is taken to be a null subject RP. Notice that the verb rasam 'painted.3ms' and the verb sajjalo 'registered.3mpl' in the sentences above carry the features necessary for the identification of pro, namely the subject RP in the highest subject position. Hence, overt realization of pro is not obligatory in JA given that it is a pro-drop language.

On the other hand, relative clauses in which a RP is realized overtly in the highest subject position are a special case where the null resumptive pro is lexicalized. Lexicalization in this instance is associated with focus on the role of the subject that pronominally resumes the initial DP topic just like 
pronominal subjects in the standard non- $\mathrm{A}^{\prime}$-dependency contexts shown in (18-20) above. The same holds for RPs in the highest subject position in relative clauses. That is, cases in which the RP has a phonetic realization bear emphatic force that is absent in relative clauses with null RPs. Consider the following examples (subject RPs are capitalized for emphasis).

\author{
22a. Juf-na l-fannaan Pilli HUWWA rasam hay l-lawha \\ saw-1pl the-artist who HE painted.3ms this the-painting \\ 'We saw the artist who painted this painting.' \\ b. et-tollaab?illi HUMMU sajjalo l-mawaad laazim ydhallo \\ the-students who THEY registered. $3 \mathrm{mpl}$ the-courses must stay. $3 \mathrm{mpl}$ \\ 'The students who registered the courses must stay.'

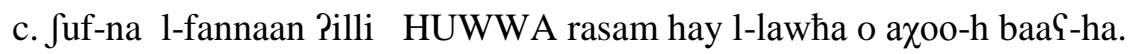 \\ saw-1pl the-artist who HE painted.3ms this the-painting and brother-his \\ sold3ms-it \\ 'We saw the artist who painted this painting and that his brother sold it.'
}

Such analysis also explains the distribution of RPs in embedded subject positions. Recall that RPs have the same distribution in both the highest and embedded subject positions. The relevant examples are repeated below.

$$
\begin{aligned}
& \text { 23a. Juf-na l-fannaan Pilli fakkarto Pinno (huwa) rasam hay l-lawha } \\
& \text { saw-1pl the-artist who thought.2pl that (he) painted.3ms this the-painting } \\
& \text { 'We saw the artist who you thought that he painted this painting.' } \\
& \text { b. jama3na et-tollaab Pilli Crefna Pinno (hummu) sajjalo l-mawaad } \\
& \text { gathered.1pl the-students who knew.1pl that they registered.3mpl the-courses }
\end{aligned}
$$

'We gathered the students who we knew they registered the courses.'

Under our analysis, subject RPs are null unless other factors require them to be overtly realized. The fact that they are null has nothing to do with the HSR. It is, rather, the pro-drop property that is responsible for the absence of RPs in such contexts in Arabic. Meanwhile, overt realization of subject RPs entails that the role of the subject in discourse is stressed, hence its presence.

The other significant environment that has not figured in the literature on resumption but one that must be accounted for concerns resumption in verbless sentences. Although such sentences contain no verb, they are full-fledged sentences with a clausal structure that parallels the structure of verbal sentences (see Benmamoun 2000, Aoun, Benmamoun and Choueiri 2010, and Abdel-razaq 2012 [26]). Relativization facts show that RPs are obligatory in the highest subject position in this type of sentence. The relevant examples are reproduced below.

$$
\begin{aligned}
& \text { 24a. 1-ktaab Pilli *(huu) Pili daye } \\
& \text { the-book that (it) mine lost } \\
& \text { 'The book that is mine is lost.' } \\
& \text { b. Sami Pilli *(huu) zameeli saafar imbaarih } \\
& \text { Sami who (he) colleague-mine left.3ms yesterday } \\
& \text { 'Sami who is my colleague left yesterday.' }
\end{aligned}
$$

One of the consequences of the present analysis is that subject RPs are the marked case, their presence is never obligatory. However, the obligatoriness of subject RPs in the sentences above seems to pose a problem for this analysis. In addition, absence of these pronouns renders such sentences unacceptable. As it turns out, such cases provide further support for our analysis. More precisely, verbless sentences contain no verbal element that carries the agreement features necessary to identify the subject RP. Absence of such features entails that such pronouns cannot be identified and must therefore be overtly 
realized to resume the relativized DP. This explains the obligatory presence of subject RPs in the sentences above.

I now turn to re-examine the HSR effects in PA under the analysis presented here. I propose that the approach developed for JA (and straightforwardly extends to LA) also applies for PA that minimally differs from JA and LA; the difference being substantially lexical and phonological in nature. The data collected for this study reveals that, contra Shlonsky (1992), PA is not in fact a language that obeys the HSR. In relative clauses, absence of a RP from the highest subject position seems to be the preferred option among Palestinian speakers. Inserting a RP in the highest subject position, however, is not ruled out, as the following cases show.

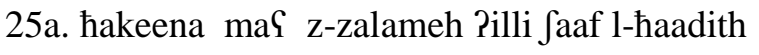

$$
\begin{aligned}
& \text { spoke.1pl with the-man who saw. } 3 \mathrm{~ms} \text { the-accident } \\
& \text { 'We spoke with the man who saw the accident.' } \\
& \text { b. hakeena maS z-zalameh Pilli HUWWA Jaaf 1-haadith } \\
& \text { spoke.1pl with the-man who HE saw.3ms the-accident } \\
& \text { 'We spoke with the man who saw the accident.' } \\
& \text { 26a. baSref } \int-\int a b b \text { Pilli Sallah s-sayaara } \\
& \text { know.1s the-guy who fixed.3ms the-car } \\
& \text { 'I know the guy who fixed the car.' } \\
& \text { b. ba9ref } \int-\int a b b \text { Pilli HUWWA Sallah s-sayaara } \\
& \text { know.1s the-guy who HE fixed.3ms the-car } \\
& \text { 'I know the guy who fixed the car.' }
\end{aligned}
$$

The (a) examples are more common in neutral relativization structures, namely structures that do not involve focus by singling out any element in the sentence. Nevertheless, the use of RPs is not unacceptable, Palestinian speakers find the RP cases where the RP is stressed to be fully acceptable. Therefore, the pattern of distribution we have here is not different from the one in JA and LA that we have been dealing with. This pattern contradicts the one reported in Shlonsky $(1992,2002)$ whereby RPs are said to be banned from the highest subject position. To confirm the results of this analysis, a re-evaluation of Shlonsky's examples by Palestinian speakers reveals that the present findings are more accurate. In other words, Palestinian speakers find the HSR examples Shlonsky provides to be perfectly grammatical as they are. Cases where a RP is inserted with a focus reading are also fully acceptable. The relevant examples are reproduced below.

$$
\begin{aligned}
& \text { 27a. 1-bint Pilli raayha Ya-l-beet } \\
& \text { the-girl that going to-the-house } \\
& \text { 'the girl that is going home' } \\
& \text { b. 1-bint Pilli HIY raayha Sa-l-beet } \\
& \text { the-girl that SHE going to-the-house } \\
& \text { 'the girl that is going home' } \\
& \text { c. 1-bint Pilli HIY raayha Sa-l-beet bet-koon zameelti } \\
& \text { the-girl that SHE going to-the-house 3sf-is colleague-mine } \\
& \text { 'The girl who is going home is my colleague.' }
\end{aligned}
$$

The fact that these examples are acceptable provides empirical evidence against Shlonsky's analysis of the HSR. Shlonsky's characterization of the PA data is not correct, hence using the HSR to explain the distribution of RPs does not yield the right results. In addition, ignoring the fact that PA, like other Arabic dialects, is a null-subject language invalidates Shlonsky's analysis of PA. Under the present analysis, however, absence of a RP in the highest subject position is attributed to the null-subject 
parameter since the verb carries the necessary features that identify the null RP. Overt realization of this RP is linked to certain discourse factors to do with emphasis and contrastive focus as we have seen in earlier cases.

\section{CONClusion}

In this paper, I have argued that the Highest Subject Restriction (McCloskey 1990) is neither autonomous nor is it a universal constraint. Instead, the paper presented evidence from Jordanian Arabic and other Levantine dialects that the HSR is a manifestation of the Pro-drop parameter that is operative in Arabic. Pursuing this line of analysis, I presented several arguments showing that relative clauses do contain RPs in the highest subject position, but they receive a null spell-out at the PF interface. I attributed this finding to the rich agreement system in Arabic whereby subject pronouns are identified without being overtly realized. The analysis developed here has wider implications for the rest of Arabic dialects that remain to be confirmed. I leave this issue open for further future research.

\section{REFERENCES}

[1] McCloskey, James (1990). RPs: A'-binding and levels of representation in Irish. In: The Syntax of the Modern Celtic Languages, ed. by R. Hendrick. Academic Press, pp. 199-248.

[2] McCloskey, James (2002). Resumption, successive cyclicity, and the locality of operations. In: Derivation and explanation in the minimalist program, ed. by S. Epstein \& T. Seely, 184-226. Blackwell.

[3] McCloskey, James (2006): Resumption. In: The Blackwell Companion to Syntax, ed. by M. Everaert \& H. van Riemsdijk. Blackwell, pp. 94-117.

[4] McCloskey, James (2011): RPs, A'-binding, and levels of representation in Irish. In: RPs at the Interfaces., ed. by A. Rouveret. John Benjamins, pp. 63-120.

[5] Shlonsky, Ur (1992). RPs as last resort. Linguistic Inquiry 23(3), 443-468.

[6] Shlonsky, Ur. (2002). Constituent Questions in Palestinian Arabic. In: Themes in Arabic and Hebrew Syntax, ed. by Jamal Ouhalla and Ur Shlonsky, 137-159. Dordrecht: Kluwer.

[7] Borer, Hagit (1984). Restrictive Relatives in Modern Hebrew. Natural Language and Linguistic Theory 2(2), 219-260.

[8] Aoun, Joseph and Y.-H. Audrey Li. 1989. Scope and constituency. Linguistic Inquiry, 20:219-251.

[9] Willis, David (2000). On the distribution of RPs and wh-trace in Welsh. Journal of Linguistics 36, 531573.

[10] Demirdache, Hamida. (1997). Dislocation, Resumption and Weakest Crossover. In: Materials on LeftDislocation. Linguistics Today Series, Vol. 14: 193-231, ed. by Elena Anagnostopoulou, Hank van Riemsdijk and Frans Zwarts. John Benjamins.

[11] Klein, Timo. (2014). Deriving a typology of resumption. In: Topics at Infl, ed. by A. Assmann, S. Bank, D. Georgi, T. Klein, P.Weisser \& E. Zimmermann. Linguistiche Arbeits Berichte 92. Universität Leipzig.

[12] Klein, Timo. (2016). Syntactic Interaction in Resumption. Proceedings of ConSOLE XXIII, 2016, 248-272.

[13] Aoun, Joseph, Lina Choueiri \& Norbert Hornstein. 2001. "Resumption, movement and derivational economy". Linguistic Inquiry 32: 371-403.

[14] Rouveret, Alain. (2011). RPs at the Interfaces. John Benjamins.

[15] Asudeh, Ash. (2012). The logic of pronominal resumption. Oxford University Press.

[16] Eid, Mushira. (1983). The Copula Function of Pronouns. Lingua 59:197-207.

[17] Eid, Mushira. (1992). Pronouns, Questions, and Agreement. In Perspectives on Arabic Linguistics IV, ed. by Ellen Broselow, Mushira Eid and John McCarthy, 107-141. Amsterdam: John Benjamins.

[18] Benmamoun, Elabbas. (2000). The Feature Structure of Functional Categories: A Comparative Study of Arabic Dialects. Oxford: Oxford University Press.

[19] Aoun, Joseph, Elabbas Benmamoun and Lina Choueiri (2010). The Syntax of Arabic. Cambridge University Press.

[20] Baoill, D. and H. Maki (2012). On the Highest Subject Restriction in Modern Irish. English Linguistics 29: 2, 357-368.

[21] Aoun, Joseph, and Elabbas Benmamoun (1998). Minimality, Reconstruction and PF Movement. Linguistic Inquiry 29: 569-597.

[22] Soltan, Usama. (2007). On Formal Feature Licensing in Minimalism: Aspects of Standard Arabic Morphosyntax. Doctoral dissertation. University of Maryland, College Park. 
[23] Chomsky, Noam. (1995). The Minimalist Program. Cambridge, Mass.: MIT Press.

[24] Kenstowicz, Michael. (1989). The Null Subject Parameter in Modern Arabic Dialects. In The Null Subject Parameter, ed. by Osvaldo Jaeggli and Kenneth Safir, 263-276. Dordrecht: Kluwer.

[25] Fassi Fehri, Abdelkader. (1993). Issues in the Structure of Arabic Clauses and Words. Dordrecht: Kluwer.

[26] Mohammad, Mohammad. (2000). Word Order, Agreement and Pronominalization in Standard and Palestinian Arabic. Amsterdam: John Benjamins.

[27] Abdel-Razaq, Issa (2012). Who Is What and What Is Who: The Morphosyntax Of Arabic WH. Cambridge Scholars Publishing. UK.

Citation: Issa Abdel Razaq. The Highest Subject Restriction and the Pro-drop Parameter in Arabic. International Journal on Studies in English Language and Literature (IJSELL), vol 5, no. 10, 2017, pp.96-106. doi:http://dx.doi.org/10.20431/2347-3134.0510012.

Copyright: () 2017 Authors. This is an open-access article distributed under the terms of the Creative Commons Attribution License, which permits unrestricted use, distribution, and reproduction in any medium, provided the original author and source are credited. 